\title{
冲绳海槽中部沉积物中热液源组分的顺序 淋滤萃取研究
}

\author{
于增慧 ${ }^{(1 *}$ ，高玉花 ${ }^{(2)}$ 翟世奎 ${ }^{(1)}$, 刘菲菲 ${ }^{(1)}$ \\ (1) 中国海洋大学海底科学与探测技术实验室, 海洋地球科学学院, 青岛 266100; \\ (2) 山东省物化探勘查院, 济南 250013 \\ *E-mail: yuzenghui@ouc.edu.cn
}

收稿日期: 2010-12-20; 接受日期: 2011-06-15

国家自然科学基金(批准号: 40306009)资助

\begin{abstract}
摘要本文针对冲绳海槽多种物源沉积作用混杂的特征, 采用顺序淋滤萃取方法对海槽中 部受热液活动影响的 $\mathrm{H} 9$ 岩芯沉积物进行了分离. 将沉积物分为可交换态、碳酸盐结合态、铁 锰氧化物结合态、有机结合态和残渣态 5 个部分, 对各个态中元素 $\mathrm{Al}, \mathrm{Ti}, \mathrm{K}, \mathrm{Fe}, \mathrm{Mn}, \mathrm{Pb}, \mathrm{Co}$, $\mathrm{Cu}, \mathrm{Ni}$ 和 $\mathrm{V}$ 组成进行了分析, 确定了不同元素在不同结合态中的分配比例. 结果表明, 残渣态 是冲绳海槽 $\mathrm{H} 9$ 岩芯沉积物中元素的重要赋存形式, 典型碎屑源组分 $\mathrm{Al}, \mathrm{Ti}$ 和 $\mathrm{K}$ 在该态中比例 高于 $95 \%$, 除 $\mathrm{Mn}$ 和 $\mathrm{Pb}$ 外其他元素在该态中比例均高于其他结合态. 可交换态、碳酸盐结合 态和有机结合态中各元素含量均相对较低, 铁锰氧化物结合态是元素除残渣态外的另一优势 赋存形式. 热液源组分主要赋存于该相态之中, $80 \mathrm{~cm}$ 以上层位沉积物中 $\mathrm{Fe}, \mathrm{Mn}, \mathrm{Pb}, \mathrm{Co}, \mathrm{Cu}$, $\mathrm{Ni}$ 和 $\mathrm{V}$ 在铁锰氧化物结合态中含量和比例相对下段显著增加, 以 $\mathrm{Mn}$ 和 $\mathrm{Pb}$ 最为典型, 比例均 超过 $50 \%$, 反映 $80 \mathrm{~cm}$ 以上层位受热液影响显著. 文中根据 $80 \mathrm{~cm}$ 以上层位铁锰氧化物结合态 中各元素含量简单估算了热液源 $\mathrm{Fe}, \mathrm{Mn}, \mathrm{Pb}, \mathrm{Co}, \mathrm{Cu}, \mathrm{Ni}$ 和 $\mathrm{V}$ 的堆积速率, $\mathrm{Mn}$ 元素堆积速率与 洋中脊和 $\mathrm{Lau}$ 海盆等构造环境产出的热液影响沉积物相当, 而 $\mathrm{Cu}$ 和 $\mathrm{Fe}$ 有所偏低.
\end{abstract}

关键词 元素堆积速率 顺序淋滤萃取 热液沉积物 冲绳海槽
海底热液沉积是洋中脊、火山活动带及其附近近 代沉积作用中不容忽视的因素, 受热液活动影响的 沉积层是地层划分中难得的标志层, 也是研究海底 热液活动演化历史及其热液活动对海洋化学贡献的 重要手段 ${ }^{[1]}$. 同时, 热液羽状体中的化学反应和物质 沉淀强烈改变了现代海底热液喷溢作用向大洋供应 的总体物质通量 ${ }^{[2 \sim 4]}$, 扩散热液羽状体下方的沉积物 中记录了从热液流体中分离出来的部分 ${ }^{[5,6]}$. 沉积物 中这些热液源组分和陆源、生物源等其他组分混合在
一起，因此对热液区附近岩芯沉积物进行淋滤萃取, 确定热液影响沉积层以及其中热液源组分分布对了 解热液活动演化以及真正确定海底热液活动的源、汇 效应具有重要意义, 尤其是在多种物源混杂、沉积速 率较高、清扫作用相对强烈的弧后盆地环境更具有特 别的意义.

冲绳海槽是西太平洋边缘、正处于初始扩张阶段 的弧后盆地 ${ }^{[7]}$, 自 1984 年在海槽中部发现热液活动 现象以来 ${ }^{[8]}$, 该区热液活动以其独特的构造背景和沉

英文引用格式: Yu Z H, Gao Y H, Zhai S K, et al. Resolving the hydrothermal signature by sequential leaching studies of sediments from the middle of the Okinawa Trough. Sci China Earth Sci, 2011, doi: 10.1007/s11430-011-4273-3 
积环境受到国内外广泛关注, 在热液区地球物理特 征、热液矿床的矿物和化学组成、热液流体特征等方 面获得了大量研究成果 ${ }^{[9 \sim 13]}$. 但是, 海槽沉积物中丰 富的陆源碎屑和生源物质的混入导致沉积物中热液 迹象相对模糊, 因此对该区受热液活动影响的沉积 物和热液活动在沉积物中的记录等方面研究较少, 部分研究涉及热液源沉积物的分布及其特征 ${ }^{[14 ~ 19]}$, 但关于热液组分的地球化学贡献的讨论相对较少.

本文针对冲绳海槽多种物源沉积作用混杂的特 征, 基于夏岛 84-1, 伊平屋和伊是名三个热液区中间 凹地取到的近代沉积物柱状岩芯, 采用顺序淋滤萃 取方法对海槽中部岩芯沉积物进行分析, 将热液源 组分和其他来源组分区分开来, 了解热液源组分在 岩芯沉积物中的变化特征, 评估海槽区热液活动对 沉积物的元素地球化学贡献.

\section{1 样品描述与研究方法}

\section{1 区域地质和样品描述}

本文研究的 $\mathrm{H} 9$ 岩芯 $\left(127^{\circ} 20^{\prime} \mathrm{E}, 27^{\circ} 40^{\prime} \mathrm{N}\right)$ 位于冲
绳海槽中部构造和岩浆活动的活跃地带, 也是 Sibeut 等 ${ }^{[20]}$ 命名的岛弧-弧后火山活动转换区(简称 VAMP, volcanic arc-rift migration phenomenon), 海槽在这一 带从北部的地壳减薄过渡为开始出现真正的弧后洋 壳. 海槽中部热液活动主要集中在这一区域, H9 岩芯 地形低洼, 水深 $1649 \mathrm{~m}$, 周围环绕已知著名热液活 动区 (见图 1). 其西南为海槽著名伊是名高温热液活 动区, 西部靠近伊平屋热液区和夏岛 84-1 热液活动 区，东北部有南奄西热液区和德之岛西海山热液区. H9 岩芯距离已知热液区中的夏岛 84 热液区最近, 大 约 $23 \mathrm{~km}$. 夏岛 $84\left(127^{\circ} 08.6^{\prime} \mathrm{E}, 27^{\circ} 34.4^{\prime} \mathrm{N}\right)$ 水深 $1540 \mathrm{~m}$, 是 1986 年海槽中最早发现热液活动的区域, 5 6 $\mathrm{m}$ 高 热液丘状体主要由非晶质硅、铁蒙脱石和铁的氢氧化 物组成, 表面盖有一层暗色绿脱石和锰的氧化物, 丘 顶喷口流体最高温度 $42^{\circ} \mathrm{C}^{[21]}$. 次年在该区上方发现 富甲烷和 Mn 的热液羽状体 ${ }^{[22]} .1988$ 年相继在伊是名 海穴和伊平屋海脊发现海槽著名的两个高温热液活 动点 JADE 区和 CLAM 区. JADE 区 $\left(127^{\circ} 04.5^{\prime} \mathrm{E}\right.$, $27^{\circ} 15^{\prime} \mathrm{N}$ ) 位于火山口状海底凹地伊是名海穴的东北 坡, 水深 1300 1450 m, 以广泛分布的硫化物烟图为

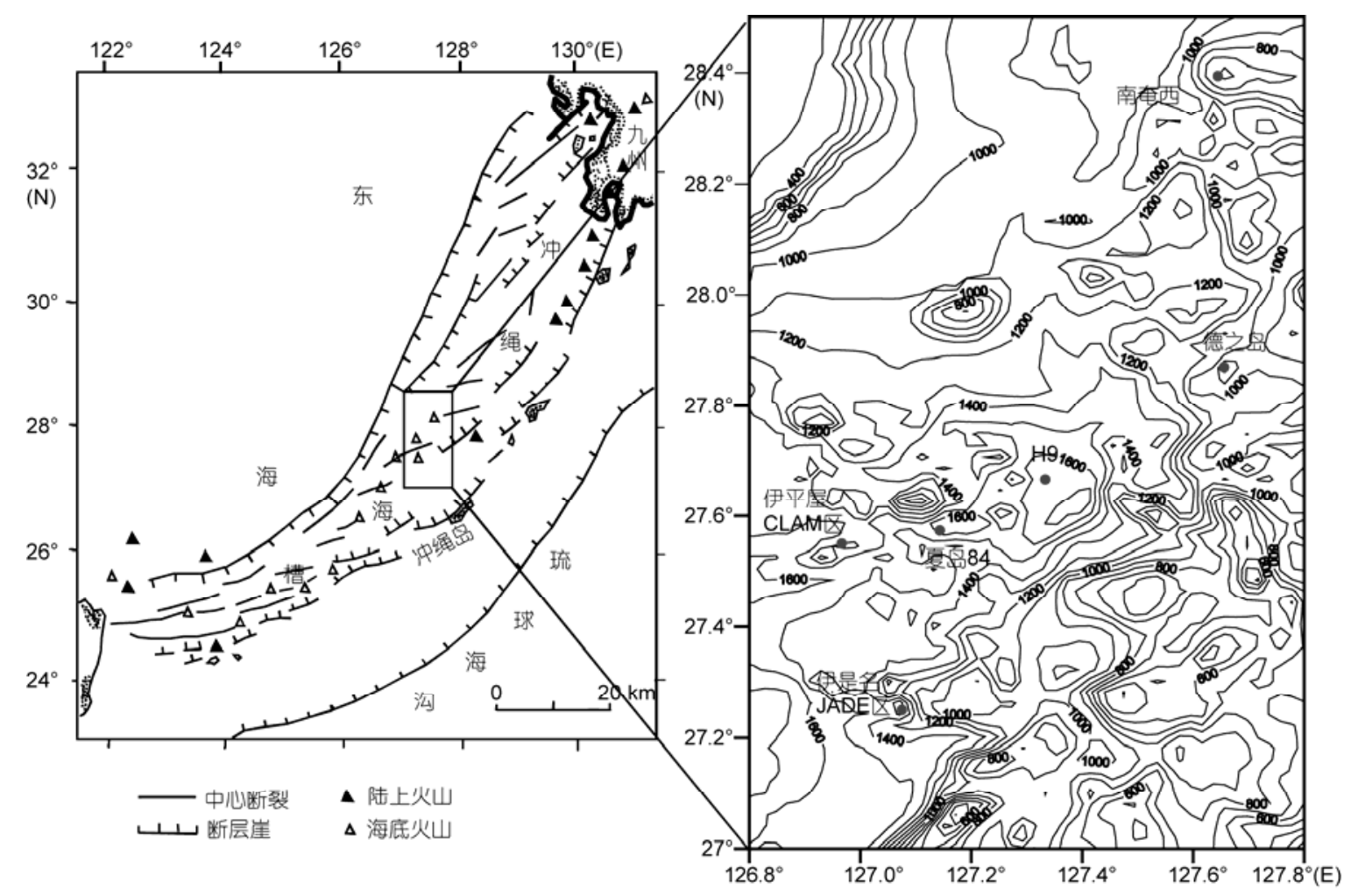

图 1 H9 岩芯位置及周边热液活动区地形图 
特征, 富 $\mathrm{Pb}-\mathrm{Zn}$ 硫化物和富 $\mathrm{Fe}$ 硫化物是常见烟图体 组成矿物, 流体最高温度 $320^{\circ} \mathrm{C}^{[10]}$. 伊平屋 CLAM 区 $\left(126^{\circ} 58^{\prime} \mathrm{E}, 27^{\circ} 33^{\prime} \mathrm{N}\right)$ 位于伊平屋海脊东端北坡的一个 小型洼地中, 该区遍布厚厚一层热液沉积, 沉积物以 碳酸盐和硫酸盐为主, 有很少量硫化物, 流体温度为 $100 \sim 216^{\circ} \mathrm{C}^{[12]} .1995$ 年在伊平屋 CLAM 区北部 $25 \mathrm{~km}$ 处发现的热液喷口流体温度高达 $311^{\circ} \mathrm{C}$, 流体成分也 与 CLAM 区显著不同, 活动烟图中以硬石膏为主, 不活动烟图中含有丰富的重晶石和闪锌矿 ${ }^{[23]}$. 南奄 西 $\left(127^{\circ} 38^{\prime} 40^{\prime \prime} \mathrm{E}, 28^{\circ} 23^{\prime} 40^{\prime \prime} \mathrm{N}\right)$ 是海槽中部另一高温热 液活动区, 位置相对靠北, 位于南奄西海丘西部火山 口内, 水深 $700 \mathrm{~m}$, 硬石膏和石膏为主的烟囱体南北 展布, 丘状矿床主要由黄铁矿和闪锌矿、方铅矿、黄 铜矿等硫化物和硫酸盐组成, 喷口流体温度 265 $278^{\circ} \mathrm{C}^{[24]}$. 另外, 在南奄西海丘南部德之岛西海山 $\left(127^{\circ} 39.3^{\prime} \mathrm{E}, 27^{\circ} 52^{\prime} \mathrm{N}\right)$ 见到铁锰氧化物型热液沉积 ${ }^{[25]}$.

岩芯为中科院海洋研究所于 1994 年在冲绳海槽 热液专项调查航次中获得, 取样方式为重力活塞取 样, 岩芯总长 $3.35 \mathrm{~m}$. 该岩芯 $0 \sim 9 \mathrm{~cm}$ 为咖啡色粘土 质沉积; 9 85 cm 段以绿灰色粉砂质粘土为主, 有孔 虫分布广泛, $35 \mathrm{~cm}$ 之上的部分有灰绿色粉砂质夹层; $85 \mathrm{~cm}$ 处出现一薄层浅绿灰色粘土质砂, 其下接约 1 $\mathrm{cm}$ 厚的浅灰色火山灰; 在 85 335 $\mathrm{cm}$ 段基本为绿灰 色或浅灰色粘土质粉砂.

对岩芯 $135 \mathrm{~cm}$ 之上部分以 $5 \mathrm{~cm}$ 间隔、之下以 $10 \mathrm{~cm}$ 间隔进行取样分析, 共分析 28 个样品. 将原始 样品研磨至 200 目以下, 在恒温 $\left(60^{\circ} \mathrm{C}\right)$ 下烘干后, 备 用.

\section{2 分析方法}

本文采用的顺序淋滤萃取法是建立在 1979 年 Tessier 等 ${ }^{[26]}$ 提出的五步顺序淋滤萃取法基础上的一 种改进方法, 包括可交换态、碳酸盐结合态、铁锰氧 化物结合态、有机结合态和残渣态 5 个部分. 前 4 个 结合态萃取流程与 Tessier 法相同, 残渣态和样品总 量采用微波消解和 ICP-AES 进行分析测定. 具体分 析流程如下:

(1) 可交换态. 将 $1 \mathrm{~g}$ 样品置于 $25 \mathrm{~mL}$ 聚四氟乙 烯离心管中, 加入 $8 \mathrm{~mL}$ 的 $1 \mathrm{~mol} / \mathrm{L} \mathrm{MgCl}_{2}$ 溶液 $(\mathrm{pH}$ 值 为 7.0). 室温下放入水浴振荡器中连续振荡 $1 \mathrm{~h}$, 振荡 过程中确保样品处于悬浮状态, 然后离心 $30 \mathrm{~min}$ (4000 r/min), 用移液枪小心地将离心管中的上清液
移入 $50 \mathrm{~mL}$ 聚四氟乙烯瓶中, 并储存于冰箱 $\left(4^{\circ} \mathrm{C}\right)$ 内 以备硝 化. 往残渣中加入 $8 \mathrm{~mL}$ Milli-Q 水后离心 30 $\min (4000 \mathrm{r} / \mathrm{min})$, 提取上清液丢弃.

(2) 碳酸盐结合态. 往第(1)步的残渣中加入 8 $\mathrm{mL} 1 \mathrm{~mol} / \mathrm{L} \mathrm{NaOAc}(\mathrm{HOAc}$ 酸化, $\mathrm{pH}=5.0$ ), 室温下放 入水浴振荡器中连续振荡 $5 \mathrm{~h}$, 再按第 1 步方法离心、 移液、洗涤.

(3) 铁镇氧化物结合态. 往第(2)步的残渣中加 入 $20 \mathrm{~mL} \quad 0.04 \mathrm{~mol} / \mathrm{L} \mathrm{NH} \mathrm{NH}_{2} \mathrm{OH} \cdot \mathrm{HCl}$ 溶液 $(25 \%(\mathrm{v} / \mathrm{v})$ $\mathrm{HOAc}$ 定容), 在 $(96 \pm 3)^{\circ} \mathrm{C}$ 下放入水浴振荡器中偶尔摚 拌 $6 \mathrm{~h}$, 再按第 1 步方法离心、移液、洗涤.

(4) 有机结合态. 往第 3 步的残渣中加入 $3 \mathrm{~mL}$ $0.02 \mathrm{~mol} / \mathrm{L} \mathrm{HNO}_{3}$ 和 $5 \mathrm{~mL} 30 \% \mathrm{H}_{2} \mathrm{O}_{2}\left(\mathrm{HNO}_{3}\right.$ 酸化, $\mathrm{pH}=2)$, 超洗 $30 \mathrm{~min}$, 在 $(85 \pm 2)^{\circ} \mathrm{C}$ 下放入水浴振荡器 中偶尔搅拌 $2 \mathrm{~h}$, 再加入 $3 \mathrm{~mL}$ 上述 $\mathrm{H}_{2} \mathrm{O}_{2}$, 在 $(85 \pm 2)^{\circ} \mathrm{C}$ 下放入水浴振荡器中间断搅拌 $3 \mathrm{~h}$. 冷却后加入 $5 \mathrm{~mL}$ $3.2 \mathrm{~mol} / \mathrm{L} \mathrm{NH}_{4} \mathrm{OAc}$, 再将样品用 $20 \%(\mathrm{v} / \mathrm{v}) \mathrm{HNO}_{3}$ 稀释 定容至 $20 \mathrm{~mL}$, 室温下反应 $30 \mathrm{~min}$, 再按第(1)步方法 离心、移液、洗涤.

(5) 残渣态. 将第 4 步的残渣蒸干后从中称取 $0.04 \mathrm{~g}$ 样品转入聚四氟乙烯消解罐. 加入 $\mathrm{HF}: \mathrm{HNO}_{3}=$ $1: 10$ 混酸, 放入微波炉中消解 $1 \mathrm{~h}$.

前面(1) (4)步过程中时刻监测 $\mathrm{pH}$ 变化, 同时制 备与每步上清液相同基体的标准溶液(加入各步萃取 剂)和空白, 以备分析. 元素总量分析的样品消解与 残渣态消解方法相同.

顺序淋滤萃取法和元素总量分析法过程中获取 的溶液中元素 $\mathrm{Fe} 、 \mathrm{Mn}, \mathrm{Ti}, \mathrm{K}, \mathrm{Al}, \mathrm{Cu}, \mathrm{Co}, \mathrm{Ni}, \mathrm{V}$ 和 $\mathrm{Pb}$ 浓度采用电感耦合等离子体原子发射光谱仪 (美国 PE 公司 DV4300 型, 简称 ICP-AES)测试, 分析工作 均在中国海洋大学海洋地球科学学院元素与同位素 地球化学实验室完成. 方法精度采用对海洋沉积物 标准样品 GBW07315 进行 5 次重复分析来控制(表 1), 对元素总量分析精度为 $3 \%$, 对淋滤萃取法各结合态 总和和标准值间相对偏差不超过 15\%, 样品回收率 介于 $89 \%$ 114\%之间.

\section{H9 岩芯沉积物顺序淋滤萃取分析结果}

\section{1 回收率分析}

元素在各结合态中的质量百分含量之和与该元 素在样品中总量的比值称为元素的回收率. 回收率 
表 1 海洋沉积物标准样品 GBW07315 总量和顺序淋滤萃取分析结果 a)

\begin{tabular}{|c|c|c|c|c|c|c|c|c|c|c|}
\hline 元素 & $\mathrm{Al}$ & $\mathrm{Co}$ & $\mathrm{Cu}$ & $\mathrm{Fe}$ & $\mathrm{K}$ & $\mathrm{Mn}$ & $\mathrm{Ni}$ & $\mathrm{Pb}$ & $\mathrm{Ti}$ & $\mathrm{V}$ \\
\hline 标准值 & 6.04 & 81.00 & 357.00 & 4.15 & 1.93 & 0.46 & 167.00 & 37.00 & 0.37 & 101.00 \\
\hline 总量分析结果 & 6.02 & 81.91 & 361.34 & 4.20 & 1.91 & 0.45 & 168.42 & 36.42 & 0.36 & 103.12 \\
\hline 相对偏差(\%) & 0.33 & 1.12 & 1.22 & 1.74 & 0.79 & 1.04 & 0.85 & 1.58 & 0.23 & 2.10 \\
\hline 萃取结果 & 5.72 & 80.75 & 398.85 & 4.19 & 1.72 & 0.46 & 154.56 & 35.65 & 0.36 & 114.48 \\
\hline 相对偏差(\%) & 5.38 & 0.31 & 11.72 & 0.96 & 10.62 & 0.00 & 7.45 & 3.66 & 0.24 & 13.35 \\
\hline 回收率(\%) & 94.6 & 99.7 & 111.7 & 101.0 & 89.4 & 100.0 & 92.6 & 96.3 & 99.8 & 113.3 \\
\hline
\end{tabular}

a) $\mathrm{Al}, \mathrm{Fe}, \mathrm{K}, \mathrm{Mn}, \mathrm{Ti}$ 的单位是\%; 其余元素单位为 $\mathrm{ppm}$. 下同

分析可以反映处理流程中元素的丢失、污染以及复 杂操作过程代入的误差, 是衡量数据质量的重要参 数.

冲绳海槽 H9 岩芯沉积物样品回收率随深度变化 见图 2, 常量元素的回收率整体较好, 均介于 $70 \%$ $130 \%$ 之间，而且绝大多数样品落入 $90 \%$ 110\%之间， 与文献中同类分析的回收率(76\% 138\%)大体相当 ${ }^{[27]}$. 微量元素在各样品中回收率相对常量元素要差, 虽 然绝大多数样品仍然介于 $70 \%$ 130\%之间, 但个别样 品中部分元素回收率可达 50\% 150\%. 从元素上看, 大部分元素表现为回收率不足, 而 $\mathrm{Mn}, \mathrm{Cu}$ 和 $\mathrm{V}$ 回收 过剩. 各元素随深度变化趋势比较一致, 反映样品差 异是控制回收率的关键因素.

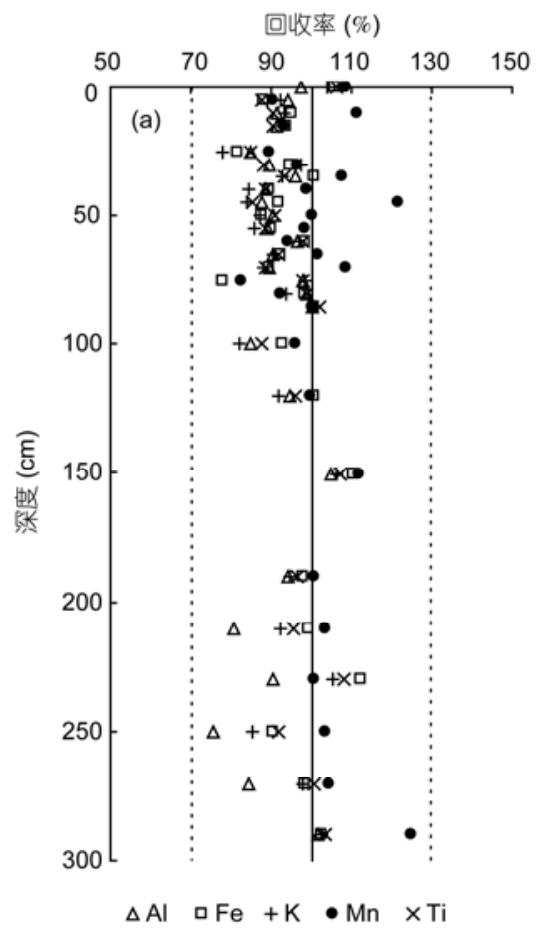

\section{$2.2 ＼textrm{H 9}$ 岩芯沉积物中元素含量及其在不同结合态 中的分布}

冲绳海槽 H9 岩芯沉积物中元素总量见表 2. Al, $\mathrm{K}$ 和 $\mathrm{Ti}$ 总含量随岩芯深度变化不大, 平均分别为 $7.0 \%, 2.2 \%$ 和 $0.35 \%$ ，与槽底表层沉积物中元素平均 含量大体相当(表 2). 元素 $\mathrm{Fe}, \mathrm{Mn}, \mathrm{Cu}, \mathrm{Co}, \mathrm{Ni}, \mathrm{Pb}$ 和 $\mathrm{V}$ 含量在岩芯 75 80 cm 以上层位(下文简称上段)明显 高于 75 80 cm 以下层位(下文简称下段), 下段各层 位元素含量与槽底表层沉积物丰度相比均有所偏低, 而上段各层位这些元素含量则较槽底表层沉积物丰 度相当或明显富集.

H9 岩芯沉积物中元素在各结合态中的分布见图 3(含量条形堆积图), 由图可见 H9 岩芯沉积物中元素

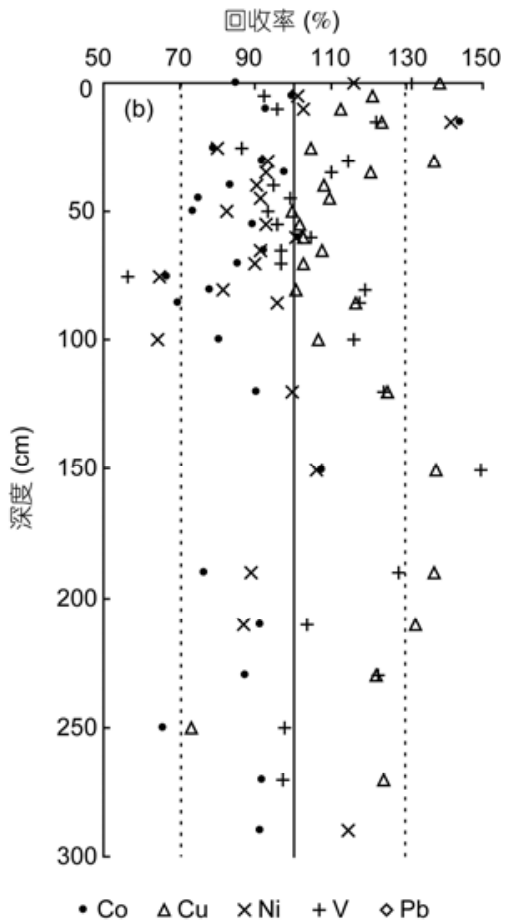

图 2 H9 岩芯沉积物样品中常量(a)和微量(b)元素回收率分布 
表 2 H9 岩芯沉积物中元素总量分析结果

\begin{tabular}{|c|c|c|c|c|c|c|c|c|c|c|}
\hline 深度 $(\mathrm{cm})$ & $\mathrm{Al}$ & $\mathrm{Co}$ & $\mathrm{Cu}$ & $\mathrm{Fe}$ & $\mathrm{K}$ & $\mathrm{Mn}$ & $\mathrm{Ni}$ & $\mathrm{Ti}$ & $\mathrm{V}$ & $\mathrm{Pb}$ \\
\hline $0 \sim 5$ & 7.4 & 22 & 44 & 3.4 & 1.9 & 0.95 & 55 & 0.32 & 94 & 97 \\
\hline $5 \sim 10$ & 7.9 & 21 & 46 & 4.1 & 2.2 & 0.65 & 53 & 0.38 & 127 & 77 \\
\hline $10 \sim 15$ & 8.3 & 21 & 50 & 4.4 & 2.4 & 0.13 & 50 & 0.39 & 139 & 78 \\
\hline $15 \sim 20$ & 9.1 & 7 & 106 & 1.8 & 5.3 & 0.12 & 4 & 0.33 & 15 & 73 \\
\hline $25 \sim 30$ & 7.7 & 20 & 34 & 3.7 & 2.1 & 0.11 & 35 & 0.33 & 108 & 47 \\
\hline $30 \sim 35$ & 7.7 & 19 & 52 & 4.0 & 2.4 & 0.46 & 54 & 0.38 & 122 & 75 \\
\hline $35 \sim 40$ & 7.4 & 20 & 53 & 3.9 & 2.4 & 0.21 & 53 & 0.36 & 122 & 79 \\
\hline $40 \sim 45$ & 8.1 & 24 & 55 & 4.6 & 2.6 & 0.19 & 61 & 0.41 & 137 & 81 \\
\hline $45 \sim 50$ & 7.9 & 24 & 55 & 4.4 & 2.5 & 0.23 & 60 & 0.40 & 139 & 82 \\
\hline $50 \sim 55$ & 7.8 & 25 & 58 & 4.5 & 2.5 & 0.42 & 67 & 0.40 & 142 & 78 \\
\hline $55 \sim 60$ & 7.6 & 23 & 55 & 4.3 & 2.4 & 0.30 & 57 & 0.39 & 136 & 66 \\
\hline $60 \sim 65$ & 7.9 & 22 & 56 & 4.4 & 2.4 & 0.17 & 56 & 0.40 & 137 & 120 \\
\hline $65 \sim 70$ & 7.8 & 21 & 52 & 4.2 & 2.2 & 0.12 & 49 & 0.38 & 136 & 74 \\
\hline $70 \sim 75$ & 7.6 & 22 & 54 & 4.1 & 2.2 & 0.11 & 47 & 0.38 & 128 & 74 \\
\hline $75 \sim 80$ & 7.4 & 16 & 37 & 3.4 & 2.3 & 0.09 & 30 & 0.36 & 97 & 48 \\
\hline $80 \sim 85$ & 6.9 & 12 & 19 & 2.6 & 2.3 & 0.08 & 17 & 0.34 & 55 & 61 \\
\hline $85 \sim 90$ & 7.2 & 13 & 19 & 2.7 & 2.3 & 0.08 & 17 & 0.34 & 55 & 32 \\
\hline $100 \sim 105$ & 8.0 & 13 & 20 & 3.0 & 2.7 & 0.08 & 17 & 0.37 & 64 & 32 \\
\hline $120 \sim 125$ & 7.5 & 12 & 20 & 2.9 & 2.5 & 0.08 & 19 & 0.36 & 66 & 41 \\
\hline $150 \sim 155$ & 7.1 & 10 & 13 & 2.5 & 2.3 & 0.07 & 10 & 0.34 & 43 & 29 \\
\hline $190 \sim 195$ & 7.6 & 12 & 13 & 2.6 & 2.4 & 0.07 & 14 & 0.36 & 45 & 28 \\
\hline $210 \sim 215$ & 7.6 & 12 & 12 & 2.8 & 2.5 & 0.07 & 13 & 0.36 & 51 & 29 \\
\hline $230 \sim 235$ & 7.2 & 11 & 11 & 2.4 & 2.3 & 0.07 & 11 & 0.35 & 42 & 33 \\
\hline $250 \sim 255$ & 8.3 & 13 & 15 & 3.0 & 2.8 & 0.07 & 143 & 0.40 & 54 & 33 \\
\hline $270 \sim 275$ & 7.6 & 11 & 12 & 2.7 & 2.5 & 0.07 & 10 & 0.36 & 51 & 33 \\
\hline $290 \sim 295$ & 8.3 & 12 & 13 & 2.8 & 2.7 & 0.07 & 11 & 0.39 & 50 & 40 \\
\hline 表层平均 a) & 7.4 & 14 & 27 & 3.63 & 1.82 & 0.259 & 39 & 32 & 0.3 & 78 \\
\hline
\end{tabular}

a) 冲绳海槽中部槽底表层沉积物元素丰度据文献[15]

在 5 种结合态中的分布极不均衡, 除 $\mathrm{Mn}$ 和 $\mathrm{Pb}$ 外, 其 他研究元素均表现为在残渣态中丰度普遍高于其他 结合态, 铁锰氧化物结合态和有机结合态次之. 可交 换态和碳酸盐结合态中各元素含量均较低. 与岩芯 上段各层位沉积物中元素含量富集相对应, 各结合 态中元素含量也大体表现为上段高于下段, 以铁锰 氧化物结合态最为明显.

为进一步明确元素在各结合态中的分布比例, 采用元素在各结合态中的浓度与其在沉积物中总浓 度之比, 即各结合态的萃取比例做萃取比例分布图 (图 4). 由图可见, 几乎全部 $\mathrm{Al}, \mathrm{K}$ 和 $\mathrm{Ti}$ 赋存于残渣态 之中, 在整个岩芯各层位沉积物中萃取比例均在 $95 \%$ 以上, 且含量随深度变化微弱. Fe, Co 和 V 也主 体赋存于残渣态, 平均萃取比例分别为 $93 \%, 89 \%$ 和 $75 \%$, 有少部分 $(3 \%$ 12\%, 0 38\% 和 5\% 17\%)赋存于 铁锰氧化物结合态, $\mathrm{V}$ 另有少部分进入碳酸盐结合态 $(1 \% \sim 15 \%)$. 上、下段间比较, $\mathrm{Fe}, \mathrm{Co}$ 和 $\mathrm{V}$ 在铁锰氧化
物结合态中的含量和比例均高于下段, 下段各层位 中三者的比例均低于 $8 \%$; 在有机结合态中上段含量 高于下段, 而萃取比例比例上、下段相当; 在残渣态 中, 含量表现为上段高于下段, 而萃取比例正好相反, 是下段高于上段.

$\mathrm{Mn}$ 和 $\mathrm{Pb}$ 的赋存形态在岩芯不同层位具有较大 变化, 特别是在上、下段之间表现出明显差别. 在元 素总量高的上段沉积物中铁锰氧化物结合态是最主 要的赋存形态, $\mathrm{Mn}$ 和 $\mathrm{Pb}$ 平均萃取比例分别为 $72.6 \%$ 和 $56 \%$, 其次是残渣态, 分别为 $22 \%$ 和 $31 \% . \mathrm{Pb}$ 还部 分进入有机结合态 $(10 \%)$. 下段沉积物中, $\mathrm{Mn}$ 和 $\mathrm{Pb}$ 含 量较低, 主要进入残渣态 $(78 \%$ 和 $84 \%)$, 部分 Mn 进入 铁锰氧化物结合态 $(16 \%)$, 但含量只是上段的大约十 分之一到百分之一. $\mathrm{Pb}$ 在岩芯下段基本不进入铁锰 氧化物结合态, 部分 $\mathrm{Pb}$ 进入有机结合态 $(8 \%)$, 反映 上、下段控制 $\mathrm{Pb}$ 进入沉积物的机制明显不同. 铁锰 氧化物结合态中的含量和比例均是上段高于下段, 

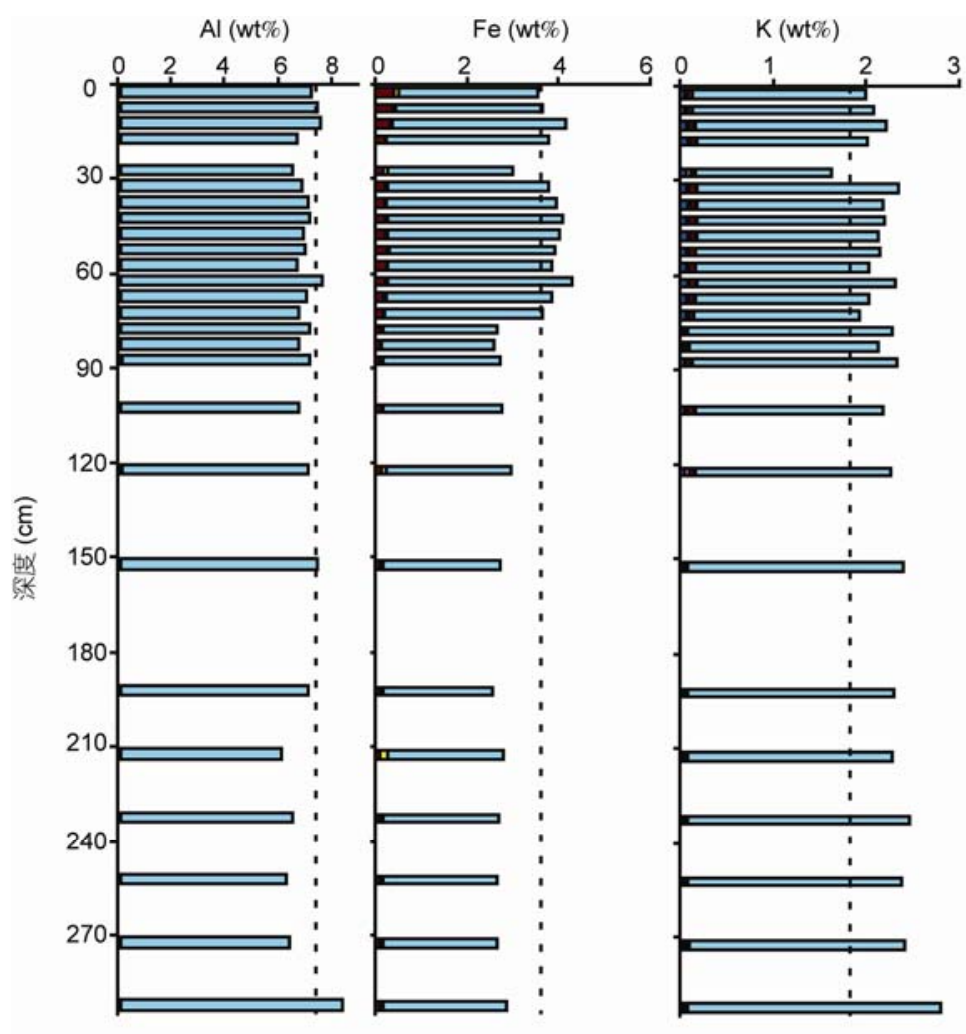

$\mathrm{Mn}(\mathrm{wt} \%)$

$\mathrm{Ti}(\mathrm{wt} \%)$
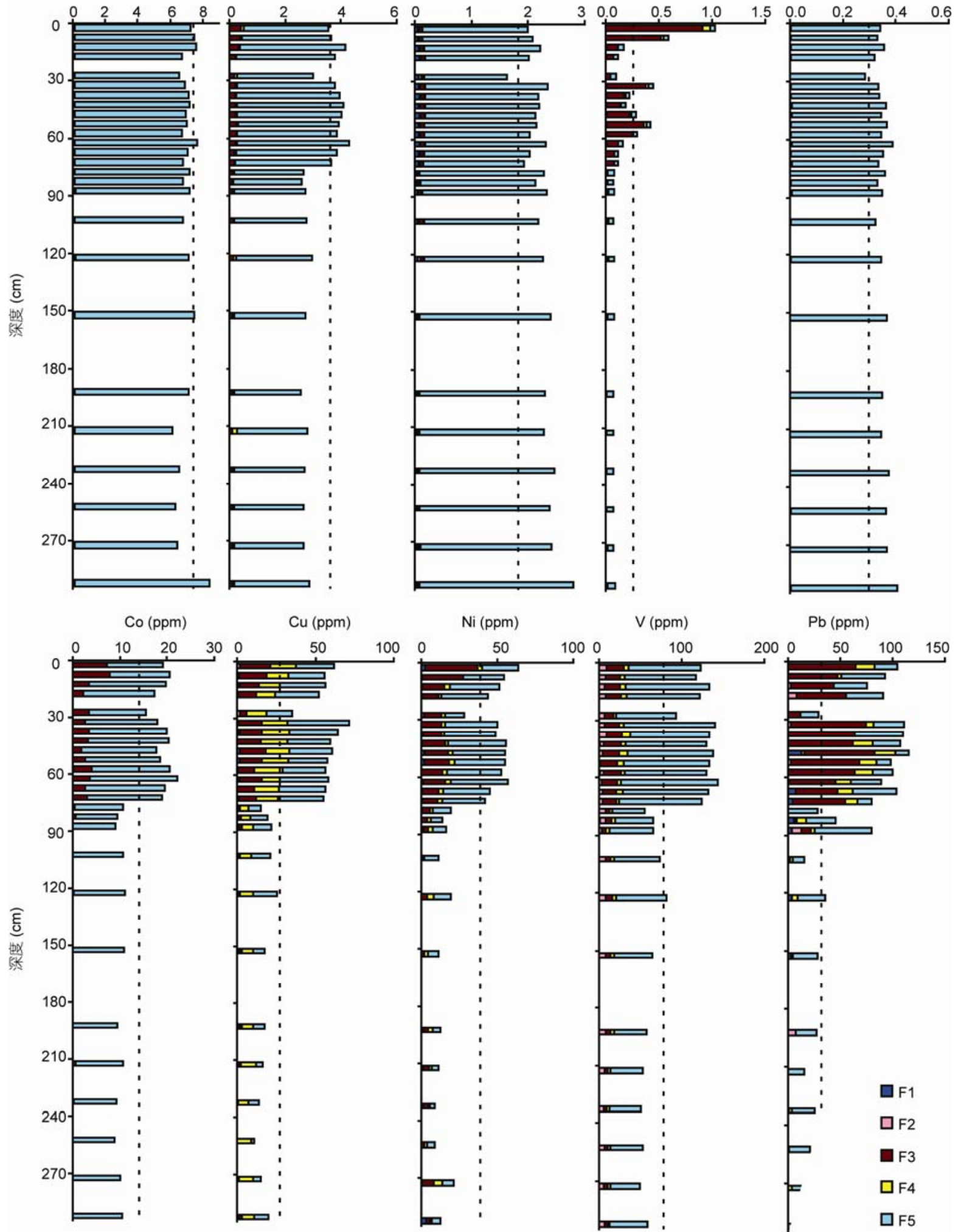

图 3 H9 岩芯各元素在不同结合态中含量的分布

虚线为槽底表层沉积物元素丰度据文献[15]. F1-可交换态; F2-碳酸盐结合态; F3-铁锰氧化物结合态; F4-有机结合态; F5-残渣态. 下图同 

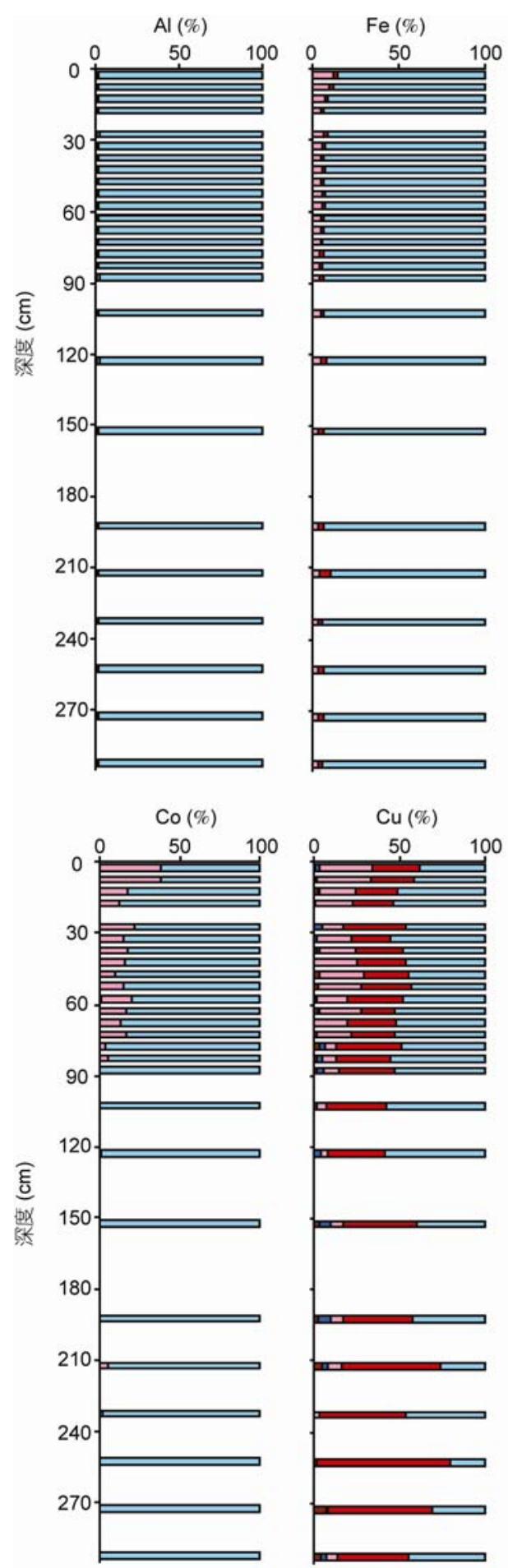
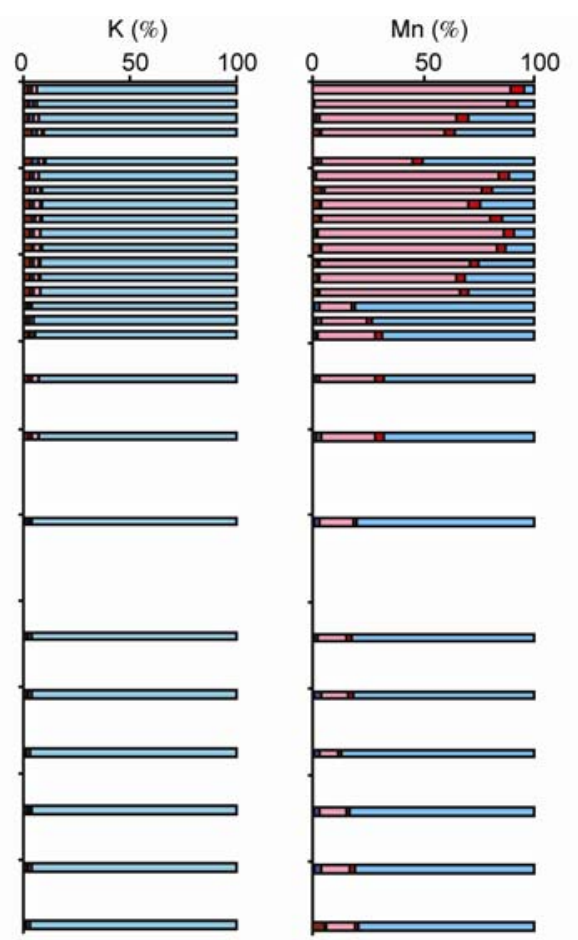

$\mathrm{V}(\%)$
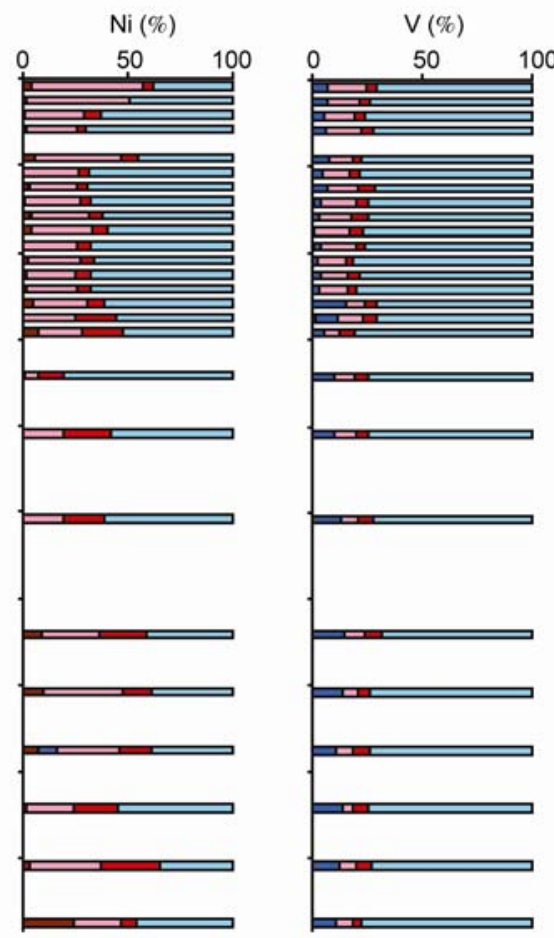
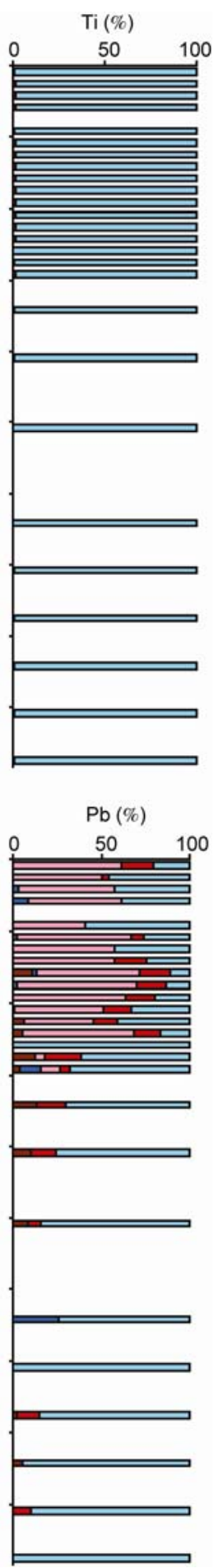

图 4 H9 岩芯各元素在不同结合态中萃取比例的分布

而残渣态仍然是比例和含量呈相反变化趋势.

$\mathrm{Cu}$ 的赋存形态在岩芯不同层位也具有较大差异. 在岩芯上段沉积物中, 主要赋存于残渣态(48\%), 其
次是有机结合态和铁锰氧化物结合态，二者萃取比 例基本相当，平均分别为 $27 \%$ 和 $23 \%$. 下段沉积物 中, $\mathrm{Cu}$ 含量显著降低, 主要进入有机结合态和残渣态 
(45\%和 $44 \%$ ), 铁锰氧化物结合态比例平均只有 $7 \%$. 铁锰氧化物结合态在上段沉积物中萃取比例明显高 于下段, 平均元素浓度更是富集了近 13 倍. 有机结 合态在上段沉积物中含量大约是下段的 2 倍, 而萃取 比例则是下段高于上段. 残渣态在上段沉积物中含 量高于下段, 而萃取比例则是下段整体高于上段.

$\mathrm{Ni}$ 主要赋存于残渣态 $(57 \%)$, 其次是铁镇氧化物 结合态 (28\%), 部分层位中有少部分进入有机结合态 (11\%). 岩芯不同层位铁锰氧化物结合态萃取比例变 化不大，上段(31\%)稍高于下段(24\%), 但该态中 $\mathrm{Ni}$ 含量在上段沉积物中明显高于下段. 有机结合态虽 在下段(17\%)沉积物中所占比例高于上段 $(6 \%)$, 但含 量上整个岩芯变化不大. 残渣态在上段沉积物中含 量高于下段, 萃取比例也是上段 (62\%) 高于下段 (51\%).

综上所述，在可交换态、碳酸盐结合态中大部分 金属元素含量较低甚至缺乏; 除 $\mathrm{Cu}, \mathrm{Ni}$ 和 $\mathrm{Pb}$ 部分赋 存于有机结合态外, 大部分元素在有机结合态中萃 取比例均低于 $5 \%$, 反映这三种结合态不是该岩芯沉 积物中元素赋存的主要形态, 与之相关的沉积作用 也不是控制元素进入沉积物的主要机制.

残渣态是文中所研究元素的重要赋存形式, 除 $\mathrm{Mn}$ 和 $\mathrm{Pb}$ 外, 残渣态中各元素的含量和萃取比例一般 都高于其他结合态, 尤以 $\mathrm{Al}, \mathrm{K}$ 和 $\mathrm{Ti}$ 最为典型, 约占 总量的 $95 \%$ 以上赋存于残渣态. 残渣态主要包括碎 屑硅酸盐和少量难溶硫化物或难溶有机质 ${ }^{[26]}$, 因此 H9 岩芯中多种元素主体赋存于残渣态的特征一方面 反映了这些元素在沉积物中主要以碎屑硅酸盐形式 赋存, 同时也反映了陆源或火山碎屑形式的供给对 该区沉积物中多种元素具有重要的贡献，这与前人 在该区研究结果相一致 $[17,18]$.

铁锰氧化物结合态是 H9 岩芯沉积物中元素的另 一主要赋存形态, 除 $\mathrm{Al}, \mathrm{K}$ 和 $\mathrm{Ti}$ 外, 其余元素在该结 合态中都有所赋存(图 3), 并表现出岩芯上段沉积物 中该态元素含量和萃取比例均明显高于下段沉积物 的格局, 以 $\mathrm{Mn}$ 和 $\mathrm{Pb}$ 最为典型. 铁锰氧化物结合态在 岩芯上段沉积物中已经成为 $\mathrm{Mn}$ 和 $\mathrm{Pb}$ 的最主要赋存 形式，比例和含量均超过了残渣态; 而在下段沉积 物中铁锰氧化物结合态只是碎屑相之后的一个附 属赋存形式, 甚至缺失. 该态中 $\mathrm{Fe}, \mathrm{Cu}, \mathrm{Co}, \mathrm{Ni}$ 和 $\mathrm{V}$ 的 含量在岩芯中的变化不如 $\mathrm{Mn}$ 和 $\mathrm{Pb}$ 明显, 但是在 $75 \sim 80 \mathrm{~cm}$ 处亦发生转折. 其上层位, 该结合态中各
元素含量和萃取比例较 $80 \mathrm{~cm}$ 以下层位均有所增高, 且各元素含量与 $\mathrm{Fe}$ 和 $\mathrm{Mn}$ 都有很好的相关性(表 3). 由此可见, 铁锰氧化物结合态是体现 H9 岩芯上、下 段沉积物中元素赋存形式差异的关键相态，与之相 关的沉积作用是控制岩芯不同层位元素组成变化的 关键因素

表 3 铁锰氧化物结合态中元素的相关性

\begin{tabular}{cccccccc}
\hline & $\mathrm{Mn}$ & $\mathrm{Fe}$ & $\mathrm{Cu}$ & $\mathrm{Ni}$ & $\mathrm{Co}$ & $\mathrm{Pb}$ & $\mathrm{V}$ \\
\hline $\mathrm{Mn}$ & 1.00 & & & & & & \\
$\mathrm{Fe}$ & 0.86 & 1.00 & & & & & \\
$\mathrm{Cu}$ & 0.75 & 0.88 & 1.00 & & & & \\
$\mathrm{Ni}$ & 0.91 & 0.96 & 0.88 & 1.00 & & & \\
$\mathrm{Co}$ & 0.81 & 0.94 & 0.85 & 0.94 & 1.00 & & \\
$\mathrm{~Pb}$ & 0.66 & 0.76 & 0.95 & 0.77 & 0.73 & 1.00 & \\
$\mathrm{~V}$ & 0.63 & 0.82 & 0.95 & 0.80 & 0.78 & 0.96 & 1.00 \\
\hline
\end{tabular}

\section{3 热液源组分的主要赋存形态}

元素结合形态的差异主要反映其进入沉积物的 机制有所不同. 因此, H9 岩芯沉积物中元素赋存形态 随深度的变化，说明了控制元素进入沉积物的机制 发生了变化.

在岩芯 75 80 $\mathrm{cm}$ 以下层位，残渣态是元素的优 势赋存形态, 除 $\mathrm{Cu}$ 和 $\mathrm{Ni}$ 外其他元素在该态所占比例 基本超过 65\%，反映该区早期沉积环境相对简单，多 数元素主要来自陆源或火山源的供给, 其他来源的 贡献相对较低.

在岩芯 75 80 cm 以上层位, 多数金属元素在残 渣态中虽含量有所增加但萃取比例相对下段有所降 低, 反映上段沉积物物源更为复杂多样. 在上段沉积 物中, $\mathrm{Mn}$ 和 $\mathrm{Pb}$ 在铁锰结合态中的优势比例，以及其 他多种与之相关元素在该态中萃取比例的明显增加, 均表明与之相关的沉积作用对岩芯上段各层位沉积 物中元素具有重要贡献，是明显不同于下段的沉积 作用. 后期成岩作用是造成岩芯沉积物顶部 $\mathrm{Mn}$ 富集 的常见原因，由于缺乏孔隙水的资料，尚无法确定本 岩芯成岩作用的影响程度. 然而, 本岩芯上部 $\mathrm{Mn}$ 的 浓度不但显著高于岩芯下段，也显著高于槽底表层 沉积物中 $\mathrm{Mn}$ 的丰度(图 3 中虚线位置), 以及非热液 活动区岩芯上部 $\mathrm{Mn}$ 的含量 $\left(4000 \mathrm{ppm}\right.$ 左右 $\left.{ }^{[28,29]}\right)$, 而 且 $\mathrm{Pb}, \mathrm{Cu}, \mathrm{Fe}, \mathrm{V}$ 和 $\mathrm{Co}$ 等多种元素在岩芯中同步富集. 这些特征表明本岩芯成岩作用的影响并不显著，不 
是控制铁锰结合态的主要沉积机制.

冲绳海槽中部热液活动发育, H9 岩芯周围围绕 多个热液活动区，东北部有南奄西热液区和德之岛 西海山热液区, 其西南为海槽著名伊是名高温热液 活动区, 西部靠近伊平屋热液区和夏岛 84-1 热液活 动区, 距离已知高温热液活动区中最近的夏岛 84 热 液区大约 $23 \mathrm{~km}$, 距离伊是名和伊平屋热液区大约 40 50 km, 并处于相对低洼地形之中, 周围高温热液 活动有可能对本岩芯产生影响. 南奄西热液区与本 岩芯之间地形相对复杂, 德之岛西海山热液区主要 为低温热液沉积, 伊平屋 CLAM 区热液流体已受到 沉积物强烈改造, 因此伊是名热液活动区、特别是夏 岛 84-1 热液区均有可能通过热液羽状体扩散对本区 产生影响, 而且由于本岩芯处于海槽中部构造火山 最活动地带, 不排除其他热液活动喷溢点的存在及 对本岩芯产生影响. 因此, 热液活动输入的大量铁锰 质氧化型沉积及其对周围水体中元素的清扫作用应 是造成 $\mathrm{H} 9$ 岩芯上段沉积物中 $\mathrm{Mn}, \mathrm{Pb}, \mathrm{Fe}, \mathrm{Cu}, \mathrm{Co}, \mathrm{Ni}$ 和 $\mathrm{V}$ 在铁锰氧化态中大量赋存的主要原因. 对冲绳 海槽热液活动区和非热液活动区悬浮颗粒物中 $\mathrm{Fe}$, $\mathrm{Mn}, \mathrm{Al}$ 和 $\mathrm{Pb}$ 元素形态分析同样发现受热液活动影响 的沉积物中 $\mathrm{Fe}, \mathrm{Mn}$ 和 $\mathrm{Pb}$ 元素在铁锰氧化态的萃取比 例较非热液影响的沉积物显著增高 ${ }^{[28]}$. 因此, 铁镇氧 化物结合态应是热液源组分在沉积物中的主要赋存 形式. 铁镍氧化物结合态中微量金属元素萃取比例在 岩芯上段的显著增加, 应反映了该区沉积晚期热液源 输入的贡献显著加强; 而其含量在岩芯上段沉积物中 随深度的变化, 反映了热液源输入强度的演变.

\section{3 冲绳海槽热液活动对沉积物的元素地球 化学贡献}

由前面讨论可知热液源组分主要赋存于铁锰氧
化物结合态中, 假定铁锰氧化物结合态中各元素含 量可以近似作为热液源组分在沉积物中的元素含量, 利用岩芯分界处 $(75 \sim 80 \mathrm{~cm})$ 沉积物 $\mathrm{AMS}{ }^{14} \mathrm{C}$ 测年结果 $5740 \mathrm{a} \mathrm{BP}^{[30]}$, 可以估算出本岩芯沉积速率大约为 $13.94 \mathrm{~cm} / \mathrm{a}$. 同时假定沉积物密度为 $1.3 \mathrm{~g} \mathrm{~cm}^{-3[31]}$, 本 文估算了 $\mathrm{H} 9$ 岩芯上段热液源的元素堆积速率，结果 见表 4 .

$\mathrm{Mn}$ 的堆积速率介于 7.14 164.87 mg cm $\mathrm{ka}^{-2}$ 之 间, 平均 $43.30 \mathrm{mg} \mathrm{cm}^{-2} \mathrm{ka}^{-1}$, 与海槽南部热液活动区 沉积物捕获器获得的悬浮颗粒的研究结果 (43.8 167.9 mg cm c $^{-2} \mathrm{ka}^{-1}$ )相比稍低 ${ }^{[24]}$, 与东太平洋 海隆以及 $\mathrm{Lau}$ 海盆估算结果大体相当 ${ }^{[32 \sim 34]}$. 元素 $\mathrm{Fe}$ 的堆积速率介于 $30.19 \sim 74.54 \mathrm{mg} \mathrm{cm} \mathrm{ka}^{-2}$, 平均 $42.22 \mathrm{mg} \mathrm{cm}^{-2} \mathrm{ka}^{-1}$, 与 $\mathrm{Mn}$ 的堆积速率大体相当, 与 海槽南部热液活动区沉积物捕获器获得的悬浮颗粒的 研究结果相比要低得多, 与东太平洋海隆以及 $\mathrm{Lau}$ 海 盆估算结果相比也有所偏低. $\mathrm{Cu}, \mathrm{Ni}$ 和 $\mathrm{V}$ 的堆积速率 大体在 $0.3 \mathrm{mg} \mathrm{cm}^{-2} \mathrm{ka}^{-1}$ 左右, 而 $\mathrm{Pb}$ 的堆积速率虽低于 海槽南部悬浮体估算结果, 但也可达 $1.3 \mathrm{mg} \mathrm{cm}^{-2} \mathrm{ka}^{-1}$, 较 $\mathrm{Cu}, \mathrm{Ni}$ 和 $\mathrm{V}$ 的堆积速率高得多, 这与海槽热液沉积 硫化物中相对贫 $\mathrm{Cu}$ 而富 $\mathrm{Pb}$ 的特征相一致 ${ }^{[10,11]}$.

元素堆积速率与热液流体特征、岩芯相对热液喷 口距离以及该区沉积速率等多种因素有关. 本研究 岩芯 $\mathrm{Mn} / \mathrm{Fe}$ 比值最高不过 0.28 , 多数高于 0.03 , 因此 应属于远端沉积物, 所以热液 $\mathrm{Mn}$ 通量相对较高, 而 其他元素通量相对较低. 同时，这种相对较高的 $\mathrm{Mn}$ 通量也说明了大颗粒物质沉降可以加速热液细颗粒 富 $\mathrm{Mn}$ 物质的沉降 ${ }^{[35]}$ ，海槽相对其他海区较高的沉积 速率可以更效的清扫热液源的金属元素. 对于 $\mathrm{Mn}$ 热 液源通量可以占到 $\mathrm{Mn}$ 元素总沉积通量的大约 40\% 89\%(Mn 在铁锰氧化物结合态的萃取比例), 而 对于陆源物质的主要组成元素 $\mathrm{Fe}$, 热液源 $\mathrm{Fe}$ 只占总 $\mathrm{Fe}$ 含量的 5\% 12\%，表明对类似 $\mathrm{Fe}$ 的陆源为主的元

表 $4 \mathrm{H9}$ 岩芯上段热液源金属元素堆积速率 $\left(\mathrm{mg} \mathrm{cm}^{-2} \mathrm{ka}^{-1}\right)$

\begin{tabular}{ccccccc}
\hline 元素 & 最大堆积速率 & 最小堆积速率 & 平均堆积速率 $(n=16)$ & 海槽南部 & Lau 海盆(Valu Fa 脊) & 东太平洋海隆 \\
\hline $\mathrm{Mn}$ & 164.87 & 7.14 & 43.30 & $43.8 \sim 167.9$ & $2.9 \sim 81.8$ & $5.4 \sim 86.0$ \\
$\mathrm{Fe}$ & 74.54 & 30.19 & 42.22 & $142.3 \sim 368.7$ & $15.5 \sim 140.2$ & $29.3 \sim 240.0$ \\
$\mathrm{Co}$ & 142.31 & 31.37 & 65.77 & & & \\
$\mathrm{Cu}$ & 351.61 & 78.22 & 239.03 & & & \\
$\mathrm{Ni}$ & 615.86 & 177.38 & 280.90 & & & \\
$\mathrm{~V}$ & 387.44 & 182.78 & 331.23 & & & \\
$\mathrm{~Pb}$ & 1304.52 & 212.86 & 959.37 & $1405 \sim 3595$ & & {$[33,34]$} \\
资料来源 & 本文 & 本文 & 本文 & {$[29]$} & {$[32]$} & \\
\hline
\end{tabular}


素, 高沉积速率可以掩盖热液源特征, 需要有效方法 进行分离.

\section{4 结论}

(1) H9 岩芯沉积物中元素在五种结合态中的分 布极不均衡, 残渣态和铁锰氧化物结合态是所研究 元素的优势赋存形态.

(2) 在岩芯 75 80 cm 以上层位, $\mathrm{Fe}, \mathrm{Mn}, \mathrm{Pb}, \mathrm{Co}$, $\mathrm{Cu}, \mathrm{Ni}$ 和 $\mathrm{V}$ 在各结合态中元素含量均高于以下各层 位, 以铁镇氧化物结合态最为明显. 铁锰氧化物结合 态中 $\mathrm{Mn}$ 和 $\mathrm{Pb}$ 比例和含量均超过了残渣态成为第一
赋存形式. 而在下段沉积物中, 铁锰氧化物结合态中 $\mathrm{Mn}$ 和 $\mathrm{Pb}$ 比例均低于 $20 \%$, 甚至缺失, 残渣态比例则 多数高于 $50 \%$.

(3) 铁锰氧化物结合态是该区热液源组分在沉积 物中的主要赋存形式, 该态中微量金属元素萃取比 例在岩芯上段的显著增加, 应反映了该区沉积晚期 热液源输入的影响显著加强.

（4）文中简单估算了热液源金属元素的堆积速 率, $\mathrm{Mn}$ 堆积速率与洋中脊和 $\mathrm{Lau}$ 海盆等构造环境产 出的热液沉积物相当, 而 $\mathrm{Fe}$ 和 $\mathrm{Cu}$ 堆积速率偏低, 这 反映了其远端热液沉积特征以及海槽高沉积速率对 热液源物质的有效清扫.

\section{参考文献}

1 Kuhn T, Burger H, Castradori D, et al. Volcanic and hydrothermal history of ridge segments near the Rodrigues Triple Junction (Central Indian Ocean) deduced from sediment geochemistry. Mar Geol, 2000, 169: 391-409

2 German C R, Campbell A C, Edmond J M. Hydrothermal scavenging at the Mid-Atlantic Ridge: Modification of trace element dissolved fluxes. Earth Planet Sci Lett, 1991, 107: 101-114

3 German C R, Klinkhammer G P, Edmond J M, et al. Hydrothermal scavenging of rare earth elements in the ocean. Nature, 1990, 345: $516-518$

4 Mottl M J, McConachy T F. Chemical processes in buoyant hydrothermal plumes on the East Pacific Rise near $21^{\circ}$ N. Geochim Cosmochim Acta, 1990, 54: 1911-1927

5 Mills R A, Elderfield H, Thomson J. A dual origin for the hydrothermal component in a metalliferous sediment core from the Mid-Atlantic Ridge. J Geophys Res, 1993, 98: 9671-9678

6 Cave R R, German C R, Thomson J, et al. Fluxes to sediments underlying the Rainbow hydrothermal plume at $36^{\circ} 14^{\prime} \mathrm{N}$ on the Mid-Atlantic Ridge. Geochim Cosmochim Acta, 2002, 66: 1905-1923

7 Sibuet J C, Letouzey J, Barbier F, et al. Back arc extension in the Okinawa Trough. J Geophys Res, 1987, 92: 14041-14063

8 Kimura M, Kaneoka I, Kato I, et al. Report on DELP 1984 cruise in the middle Okinawa Trough. Part V: Topography and geology of the central grabens and their vicinity. Bull Earthq Res Ins Univ Tokyo, 1986, 61: 269-310

9 Gamo T, Sakai H, Ishibashi J, et al. Growth mechanism of the hydrothermal mounds at the CLAM site, Mid-Okinawa Trough, inferred from their morphological, mineralogical, and chemical characteristics (in Japanese). JAMSTECTR Deep-sea Res, 1991, 7: 163-184

10 Halbach P. Geology and mineralogy of massive sulfide ores from the central Okinawa Trough, Japan. Econ Geol, 1993, 88: 2210-2225

11 Halbach P, Hansmann W, Koppel V, et al. Whole-rock and sulfide lead-isotope data from the hydrothermal JADE field in the Okinawa back-arc trough. Mineralium Deposit, 1997, 32: 70-78

12 Sakai H, Gamo T, Kim E S, et al. Unique chemistry of the hydrothermal solution in the Mid-Okinawa trough backarc basin. Geophys Res Lett, 1990,17: 2133-2136

13 Chiba H, Nakashima K, Gamo T, et al. Hydrothermal activity at the Minami-Ensei knoll, Okinawa Trough: chemical characteristics of hydrothermal solutions (in Japanese). JAMSTECTR Deep-sea Res, 1993, 9: 271-282

14 Masuda H, Ishibashi J, Kato Y, et al. Oxygen isotope ratio and trace element composition of hydrothermal sediments from Okinawa Trough, collected with Shinkai 2000, dive 231 (in Japanese). JAMSTECTR Deep-Sea Res, 1987, 3: 255-231

15 赵一阳, 鄢明才. 冲绳海槽海底沉积物永异常——现代海底热水效应的“指示剂”. 地球化学, 1994, 23: 132-139

16 赵一阳, 翟世奎, 李永植, 等. 冲绳海槽中部热水活动的新记录. 科学通报, 1996, 41: 1307-1310

17 孟宪伟, 王永吉, 吕成功. 冲绳海槽中段沉积地球化学分区及其物源指示意义. 海洋地质与第四纪地质, 1997, 17: 37-43

18 高学民, 林振宏, 刘兰, 等. 冲绳海槽中部表层沉积物的地球化学特征和物源判识. 海洋学报, 2000, 22: 61-66 
19 Marumo K, Hattori K H. Seafloor hydrothermal clay alteration at Jade in the back-arc Okinawa Trough: Mineralogy, geochemistry and isotope characteristics. Geochim Cosmochim Acta, 1999, 63: 2785-2804

20 Sibuet J C, Letouzey J, Barbier F, et al. Back arc extension in the Okinawa Trough. J Geophys Res, 1987, 92: 14041-14063

21 Kimura M, Kato Y, Tanaka T, et al. Submersible SHINKAI 2000 study on the central rift in the middle Okinawa Trough (in Japanese with English Abstract). JAMSTECTR Deep-Sea Res, 1987, 3: 165-196

22 Ishibashi J I, Gamo T, Sakai H, et al. Geochemical evidence for hydrothermal activity in the Okinawa Trough. Geochem J, 1988, 22: 107-114

23 Chiba H, Ishibashi J I, Ueno H, et al. Seafloor hydrothermal systems at North Knoll, Iheya Ridge, Okinawa Trough (in Japanese with English Abstract). JAMSTEC J Deep-Sea Res, 1996, 12: 211-219

24 Glasby G P, Notsu K. Submarine hydrothermal mineralization in the Okinawa Trough, SW of Japan: An overview. Ore Geol Rev, 2003, 23: 299-339

25 蒋富清. 冲绳海槽现代海底热液活动研究概况. 海洋科学, 1998, 6: 25-28

26 Tessier A., Campbell P G C, Bisson M. Sequential extraction procedure for the speciation of particulated metals. Anal Chem, 1979, 51: 844-851

27 Marin B, Valladon M, Polve M, et al. Reproducibility testing of a sequential extraction scheme for the determination of trace metal speciation in a marine reference sediment by inductively coupled plasma-mass spectrometry. Anal Chim Acta, 1997, 342 : 91-112

28 李军. 冲绳海槽中部 A7 孔沉积物地球化学记录及其对古环境变化的响应. 海洋地质与第四纪地质, 2007, 27: 37-45

29 Hsu S C, Lin F J, Chung Y, et al. Observed sediment fluxes of the southwestern most Okinawa Through enhanced by episodic events: Flood runoff from northeastern Taiwan river and great earthquakes. Deep-Sea Res, Part I. 2004, 51: 979-997

30 Shikui Z, Zenghui Y, Tongjun D. Elemental geochemical records of seafloor hydrothermal activities in the sediments from the Okinawa Trough. Acta Oceanolog Sin, 2007, 26: 53-62

31 翟世奎, 许淑梅, 于增慧, 等. 冲绳海槽北部两个可能的现代海底热液喷溢点. 科学通报, 2001, 46: 490-492

32 Daessle L W, Cronan D S, Marchig V, et al. Hydrothermal sedimentation adjacent to the propagating Valu Fa Ridge, Lau Basin, SW Pacific. Mar Geol, 2000, 144: 479-500

33 Leinen M, Stakes D. Metal accumulation rates in the central equatorial Pacific during Cenozoic time. Bull Geol Soc Amer, 1979, 90: 357-375

34 Lyle M W, Owen R M, Leinen M. History of hydrothermal sedimentation at the EPR, 19². Initial Reports of the DSDP, 1986, 92 : 585-596

35 Lavelle J W, Cowen J P, Massoth G J. A model for the deposition of hydrothermal manganese near ridge crests. J Geophys Res, 1992, 97 : 7413-7427 